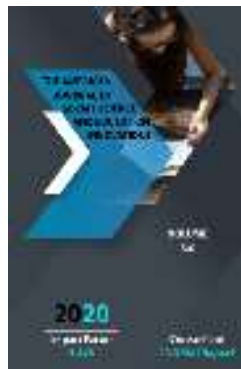

Journal Website: http://usajournalshub.c om/index,php/tajssei

Copyright: Original content from this work may be used under the terms of the creative commons attributes 4.0 licence.

\section{Linguapragmatic Features Of Exclamations In The Process Of Speech Communication}

\author{
Muhabbat Madaminova \\ Basic Doctoral Student Of Andijan State University (Phd), Andijan City, Republic Of \\ Uzbekistan
}

\title{
ABSTRACT
}

In this article, the linguistic features of the speech communication process based on the lexicalgrammatical nature of the specific syntactic device-vowels were studied on the basis of a substantive approach. This article is based on examining the lexical-grammatical features of exclamations in the process of speech communication on the basis of a substantial approach, or a complete description of the phrase exclamation. The general characteristics, lexical-semantic features, morphologicalsyntactic expression, structure of the impulse are described in detail, as well as the place of the motivation in speech, intonation, historical development, methodological nature, separated and organized impulses.

\section{KEYWORDS}

Pragmalingvistics, exclamation point, structure, predicate, communicant, syntactic device, speech.

\section{INTRODUCTION}

Pragmalinguistics requires a new approach to the study of language units at different levels in the process of verbal communication. Communicators understand each other through conscious thinking in the process of verbal communication.
Speech is a means of communication between the addressee and the recipient, that is, a complex and uniquely organized form of speech, as the main factor that introduces the purpose of the addressee to the addressee. The meeting process, of course, has a specific 
purpose. The goal is achieved through the combination of pragmatic factors with linguistic events. In this sense, "linguistic pragmatics as a new field of linguistics studies the hidden propositions related to the internal purpose of the subject of speech".

"... to go beyond the syntactic realm in the analysis of speech and to study the discursivepragmatic nature of this phenomenon has brought linguistic research to a new level". Thus, there is a growing need to study the place and role of syntactic devices in text pragmatics.

\section{MATERIAL AND METHODS}

It is well-known that adverbs, introductions and prefixes, separated parts, and adverbs are simple sentences that are complicated. Such sentences are complex both in form and in content. Complex sentences have their own peculiarities, unlike simple and compound sentences. They consist of followings:

Complex sentences express not only a single goal, but also a complex idea.The parts that make up a complex sentence are related to the interpretation of the general content of the sentence. The relationship between the exclamation,the introduction, and the exclamations is the relationship between the speaker and the syntactic situation expressed through the speech. Such an attitude "represents a subjective attitude".

In complex, simple sentences, such an approach expands the meaning of the sentence. While exclamations represent a motivational relationship, introductions represent a modal relationship, exclamations represent a relationship of perception and influence.
M. Kasimova also studies the invocations as a unit that introduces a subjective relation to the introductory connection [1], that is, does not enter into a syntactic connection, but is connected only by the content. While acknowledging that A. Nurmanov and AR Saifullayev's approach to the issue was correct, he stressed that another linguistic unit - the calls - were ignored. In this case, it is not assumed that the preposition is in the preposition. Encouragement often serves as an encouragement, as does the introduction. Such urges can give an emotional color to the content of the speech and change its pragmatic state. [See: Kasimova M. Linguistic features of the individuality of artistic speech (based on the works of TogaiMurod)].

\section{RESULTS}

Exclamation, by their lexical and grammatical nature, are a powerful linguistic unit that can influence the content of a speech situation. A word or phrase that represents the subject or object of a speaker's speech is called a consonant. and in the end. AR Saifullaev's treatise "Undalma in modern Uzbek literary language" describes in detail the general characteristics, lexical-semantic features, morphological-syntactic expression, structure of undalma, its structure, as well as its tense. There is also talk of the nature, the separated and the organized urges. It is emphasized that the treatise has grammatical features, as it is the equivalent of the possessive parts of speech, possessive, participle, complement, case and determiner.

We support the existence of motivation in speech, that is, as an integral part of the system, in summarizing the views of $A$. Saifullayev and M. Kasimova, the classification of encouragement, introduction and exhortation as "tertiary parts of speech." 
The exclamation does not make grammatical connection with the parts of speech, but also expresses the motivational attitude of the speaker, the subject of the listener, and in the literary text the subject and concepts to which the listener's attention is directed. What discourse is used to express an objective situation is determined only by the discursive content of the speech situation. In this regard, the pronouns can express a number of semantics in the positive, negative, neutral tenses, such as respect, caress, cut, threat, curse, contempt, flattery.

Exclamations are actively used in oral discourse, literary and journalistic texts. Their use also allows for the syntactic expression of expressiveness.

Motivations cannot be adapted, controlled, or cohesive with the primary and secondary parts of a sentence. However, they are one of the necessary parts of a sentence, depending on the parts of the sentence or the whole sentence. and enters into a specific grammatical connection with the general content of the sentence [2].

M. Yuldashev gives name toapostrophes as the units of appeal: "The units of appeal are widely used in our daily life, in the activity of speech in the process of speech. Speech units are used in speech to attract the attention of the listener, to address, to encourage. Such units also express communicative relationships between the speaker and the listener, such as intimacy, respect, trust, distance (subordination), disrespect, and mistrust. One of the lexical and grammatical features of an adverb is that it can describe the person or object it represents."

I. Rasulov divides the apostrophes into 2 groups:
1. Stylistic neutral tones.

2. Evaluation characteristics of the expressive impulse.

In many cases, a person's first name, last name, title, and kinship can have a neutral meaning.

"Are you curious, Rashid? What are you ashamed of?" Instead, talk about yourself. (U. Hamdam, "Balance")

"But when is my sister Robbie coming?" (G. Hoshimov, "Between Two Doors")

"Dad, what did you bring me?" (Orally)

In official texts, mainly neutral exclamations are used:

Dear senators! In order to increase the efficiency of the work of the upper house, I believe that in the near and long term it is necessary to implement the following important tasks. (From the speech of the President of Uzbekistan)

Exclamations that express the characteristics of the assessment have an emotionallyexpressive color, not only express the addressee of the speech, but also characterize it and express their attitude to it [3].

Such exclamations are naturally formed through words that have a negative connotation, such as metaphorical lexemes, subjectively valued expressions, vulgarisms, barbarisms, and the repetition of pronunciations.

\section{Metaphorical exclamation:}

"Did I say anything bad to you, dog?"

(TogaiMurod "Firethe night before")

When I opened my eyes, Haji's grandmother was smiling.

"Why are you biting, puppy?" He said, stroking my head. 
(OtkirHoshimov"World Affairs")'

\section{DISCUSSIONS}

In the first sentence, the word "dog" has a negative connotation based on metaphor and expresses hatred towards the listener, while in the second sentence, the word "puppy" is applied to the child and means caress[4].

Vulgarism-based exclamation:'

"Pikillama-e-e, enagar! What, I eat, are you empty-handed?"

(TogaiMurod, “The steppes left by my father”)

\section{Exclamation is also based on barbarism:}

"Look at me, victim! Do you have a tongue? Tell me, then?" (TogaiMurod, "The steppes left by my father")

"Bless you, dear!"

"Yes, you're gone!" Sell us your dope, sir!

(G. Hoshimov, "Between Two Doors")

In these examples, too, the word "victim" has a negative connotation in the sense of humiliation, contempt, and insult, while the barbarism of "gyro" is a distorted variant of the word "hero" in the colloquial speech and means more affectionate to a young child[5].

\section{Exclamation in the form ofabbreviated name:}

In colloquial speech, there is a method of abbreviating nouns, which means caressing, intimacy, closeness. The creators use this situation in the literary text as a stylistic tool in the speech of the character.

"Yes, Nilu, are you tired? Are you going to visit?" I said fondly.

"I was born today," he said, rolling his black eyes and smiling. (J. Hashimov, "World Affairs")
"Yes, Robbie, read!" said my grandfather, crawling out onto the dark porch. (G. Hoshimov "Between two doors")

"Oh, is my brother bad?"

"Nega, crazy?"

"He kicked and broke the pumpkin I had just made!" (J. Hashimov, "World Affairs").

The word "insane" actually means insane, mentally ill, but in colloquial speech the form "insane" is used in the sense of intimacy, caress[6].

\section{CONCLUSIONS}

Above, Ermon's grandfather's thin voice comes:

"Shoshmans, popuks, shoshmangs, koravoys, and five or ten more times, it's enough for all of you." (J. Hashimov, "World Affairs")

- Mulberry burns the heart, puppies. Come on, let's have some tea.

\section{(J. Hashimov, "World Affairs")}

Grandpa Ermon doesn't call anyone by name: for him, all girls are navels and all boys are black. In order to ensure the individuality of the character's speech, the writer uses specific prompts in his speech, which emphasizes the character of a pure, intelligent person, serves to complement his childhood, his simple actions.

"Wow, poshsha-a-a!" What have you done? (J. Hashimov, "World Affairs")

The ambiguity of the meaning of this sentence is due to the method of pronouncing the letter "a" (in writing it is expressed in several letters). This method is used mainly as a methodological tool in oral speech and in the literary text.

In the course of the conversation, the intensification of the conflict between the 
communicators - the expression of the phenomenon of gradation through exhortations - is observed, which allows them to perceive the speech situation in a blistering way[7].

- Husanhuja! Husanhuja!

"What?" Came a thin voice.

"Take an apricot." Oh, the top of the horn. Be quick!

"I'm going to fall."

"You won't fall."

Husanhuja came closer, slapping his long pants.

- A piece of wood?

"All right," said Clock indifferently.

The apricot was high. Husanhuja would cut a piece of mulch, and the top of the cup would not reach the horn. He was sweating. The other children are watching in silence. Finally, the beetle touched the horned apricot tree. Three apricots fell to the ground. Husanhuja ran to fetch him.

\section{"Mang, Soat aka!"}

"Don't wash, you idiot!" "The clock is ticking." "I won't add it to the soil!"

Husanhuja came to the river bank with his stomach and washed the apricots.

"Mang, brother!"

"It's cracked, donkey!" I need a leg! "The clock threw the apricots into the river." "Come on out!" He exclaimed. "Cut it off!" [UtkirHoshimov, "Lives in the Dream," p.]

Teenagers - During the meeting between Husanhuja and Saatortasi, the speaker's subjective negative assessment of the listener is manifested through the intensification of Husanhuja, an idiot, a donkey. Given that the reality of the work dates back to the former Soviet era, the author's goal in this discursive situation is to expose the actions of an artificial ideology based on the principle of "divide and rule" through the phenomenon of allusion. (Allusio - (Lat. Allusio - sign, humor) - a stylistic method based on reference to a real political, domestic, historical or literary fact, which is considered familiar to all) [8].

\section{ACKNOWLEDGEMENTS}

It can be seen that the image of the clock is embedded in the process of forming the mentality of young children, even with the aim of creating discord among the representatives of one nation on a class basis. In order to maximize the negative tone, the use of the adjective "donkey" in relation to the child (person) occurs on the one hand through the metaphorical meaning of the word, and on the other hand through the reinforcement of the vowel "sh" with a vowel. As a result, Saat's hatred for Husanhuja, a "member of the opposite class," is strong.In conclusion, a unique syntactic device - a new approach to linguistics and to the study of the linguapragmatic features of apostrophe on the basis of new methods of analysis can be a rich source of material for our science.

\section{REFERENCES}

1. Mahmudov N., Nurmonov A. Theory of the Uzbek language. The T., Teacher, $1995 \mathrm{y}$.

2. Saifullaev A. "In the current Uzbek literary language undalma" T., Fan,1968 y.

3. Safarov Sh. The next tasks of linguistics/ / Foreign philology. Number 3, $2016 \mathrm{y}$.

4. Veerudu A., Rasulov District. R. Kolonoros., Rustamov Kh. Uzbek tristique. So, Beketovka, 1983 y.

5. Kosimova $M$. Distinctive symbol of linguistics feature (Togay Murod asarlari, founded). FFN Diss. T., 2007. 
The American Journal of Social Science and Education Innovations (ISSN - 2689-100x)

Published: September 14, 2020 | Pages: 146-151

Doi: https://doi.org/10.37547/tajssei/Volume02Issue09-21

6. Aronov D., Z. Mamajonov, M. Sheraliyev. Dictionary of literary studies. T., "Akademnashr", 2010.

7. Hakimov M. Fundamentals of Uzbek pragmalinguistics. So, Academys,2013y.

8. F. A. Abdurakhmonov,S. S. Shoabdurakhmanov, Fundamentals of Uzbek pragmalinguistics, A.P.Hajiev.Uzbek language II tom.T., "Science" 1976 y. 